\title{
In memoriam Lawrence R. Freedman (1927-2020)
}

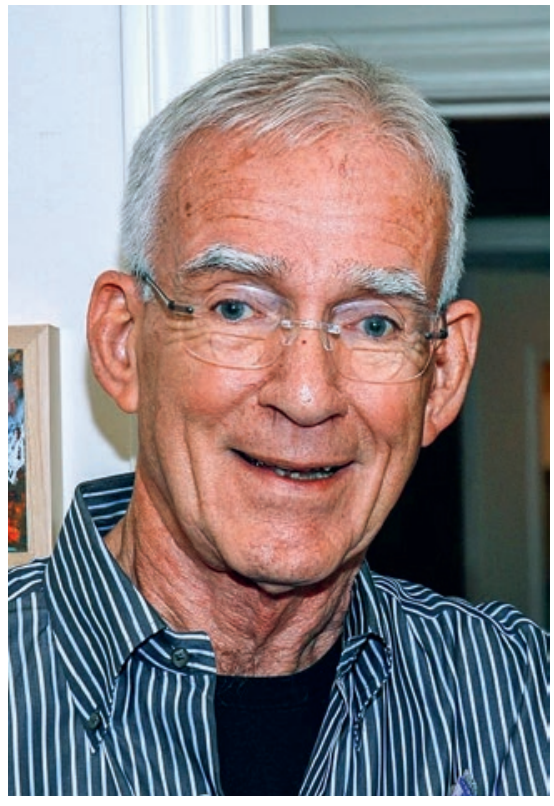

Lawrence R. Freedman

Le Professeur Lawrence R. Freedman est décédé à l'âge de 93 ans le 12 décembre 2020 à Los Angeles.

Né à New York, il a fait des études de médecine à Yale University où il a obtenu son titre de MD avant de s'engager dans une carrière académique et de devenir professeur ordinaire et chef des maladies infectieuses.

\section{Il a profondément modernisé la Clinique} médicale du CHUV, en créant plusieurs divisions de spécialités de la médecine interne.

En 1973, peu après un séjour sabbatique comme professeur invité à l'Institut Suisse de Recherche Expérimentale sur le Cancer à Epalinges, il est choisi par l'Université de Lausanne pour le poste de chef de la Clinique médicale au Centre hospitalier universitaire vaudois (CHUV) et professeur ordinaire de médecine interne, à la succession du Professeur Alfredo Vannotti.
Il va profondément marquer et moderniser l'organisation clinique et académique de la clinique, notamment en créant plusieurs divisions de spécialités de la médecine interne, et en y appelant des spécialistes de renommée internationale. Sous son impulsion, la médecine interne se développe et devient un Département, et de nouveaux domaines de recherche de haut niveau voient le jour. Son influence sur le développement des maladies infectieuses s'étend à toute la Suisse.

Par sa personnalité forte et rayonnante, il a formé une génération d'internistes et enthousiasmé des volées d'étudiants en médecine.

Avec plusieurs collaborateurs de la région, il poursuit sa recherche dans le domaine de la physiopathologie de l'endocardite infectieuse, et le modèle animal qu'il développe est indiscutablement la clé des progrès réalisés dans ce domaine. Par sa personnalité forte et rayonnante et grâce à ses connaissances étendues, il a formé une génération d'internistes qui lui vouent une grande reconnaissance et il est parvenu à enthousiasmer des volées entières d'étudiants en médecine.

En 1980, Larry Freedman retourne aux Etats-Unis où il est nommé chef du Département de médecine interne du VA Wadsworth Medical Center, University of California, Los Angeles.

Outre sa passion pour la médecine et pour la recherche, Lawrence Freedman aimait la musique, l'opéra, le piano dont il a joué toute sa vie, et adorait les courses en montagne, en Engadine particulièrement, où il est revenu souvent.

Lawrence Freedman laisse son épouse Rina, ses deux filles Julia et Leora, et deux (grands) petits-enfants, à qui ses anciens élèves et amis tiennent à témoigner toute leur sympathie.

Michel Glauser, Professeur honoraire Patrick Francioli, Professeur honoraire 